\title{
Bridging the gap between university and upper secondary school English studies: The ULE project
}

\author{
Terry Walker and Rachel Allan, Mid-Sweden University
}

\section{$1 \quad$ Introduction}

This paper reports on a collaboration between an upper secondary school and the English section of the Humanities department at Mid-Sweden University in Sweden, as well as the outcome of a pilot project, and the way forward. The collaboration project is entitled "An Online Introduction to University-level English Studies for Upper Secondary School Students" (abbreviated to University-level English, or ULE) and aims to:

- give upper secondary school students a taste of university-level English studies as part of their English coursework

- provide teachers with insights into university-level English studies and how it relates to upper secondary school level

- provide the English section with insights into how university-level English studies relate to upper secondary school level

- provide a corpus for teaching English on the upper secondary school teacher education programme at Mid-Sweden University

- provide a corpus for research into the language of upper secondary school students for both the English staff and students on the upper secondary school teacher education programme at Mid-Sweden University.

The pilot project ${ }^{1}$ involved three university lecturers of English, one teacher of English at upper secondary school, and 32 students of English in their second year of upper secondary school studies (English 6). The project is detailed in the following section.

As part of the project, students wrote a short essay and a brief peer review of a fellow student's essay (see Section 2). The material was then analysed in terms of the vocabulary level of the class as well as the students' competence in and awareness of language and text structure. The aims and research context of the analysis are explained in Section 3.1, and Sections 3.2 and 3.3 deal with the analysis. The implications of the ULE project for future collaboration, research, and teaching are considered in Section 4. 


\section{The ULE project}

\subsection{The process}

After initial discussions between ourselves and the upper secondary school, it was decided to only involve one teacher and one class for the pilot project. The project was set up using the open access learning management system Moodle (see https://moodle.org). This learning platform allowed us to enrol secondary school students and teachers onto the specially-designed module, where instructions, lectures, two short assignments, and feedback could be given by university teachers, and where students could submit their work. This also reflects the mode of instruction for our online English courses at Mid-Sweden University. The content was designed to reflect first-term undergraduate university-level English language studies. The teacher then explained to the class about participating in the project as part of their classwork, and received a positive response. In the following lesson, students received two articles, together with a glossary for each, to read in class in advance of our meeting the students to introduce the project.

To guide the students into the project, we met the students during their regular English class, and introduced the students to the aims and content of the project, the theme, topic and assignments (see 2.2), and the learning platform (including how to log-in and how to negotiate the platform). They also received information on how to log-in, and how to do the first assignment, on paper. The students were at this point asked to sign a permission form allowing us to use their work (which would of course be anonymised) for subject didactic and/or linguistic research and for teaching on the upper secondary school teacher education programme at Mid-Sweden University. It was explained to them that although the assignments were compulsory, as part of their school coursework, giving permission for us to use the material was entirely their choice. Happily, all students chose to sign the form, including a few students who were absent from the initial introductory session. For those who missed the session, a written instruction guide was uploaded in Moodle.

\subsection{Classwork and the assignments}

The theme for the project, the US presidential election, was decided on in collaboration with the teacher, the idea being to select a topical issue from the English-speaking world. We based the classwork and written assignments on one of the assignments on our first-term undergraduate English course at MidSweden University. The classwork was designed to take up as many as six of their scheduled English classes at upper secondary school (or part of these classes). The first class was when they were to read the two articles, the second 
was our introduction to the project, the third was when they were to log-in to Moodle and prepare for the written assignment, the fourth was when they should do the written assignment, an essay, and in the fifth class they were to do a peer review. The sixth class was when we returned to give feedback on their input, as well as get feedback on the project.

The two articles the students read prior to our introduction were about Hillary Clinton's health. The topic of the assignments was 'bias in the media' and thus we were able to use these two articles as examples when we explained how to recognise the bias in texts during our introductory session (the short lecture was recorded by both the authors, so that students could revisit the topic, but also witness our own bias in how we chose to narrate the lecture). In Moodle, students were given commentary on and examples of bias in the two articles they had read, and their assignment in the next class was to check these commentaries and then read, discuss, and make notes on a third article on Clinton's health, in preparation for writing an essay on bias in the third article in the following class. The instructions for writing the essay were as follows:

Write a text (of about $350-400$ words) that briefly describes the article, and explains which candidate the article favours and which candidate the article disfavours. Give examples of bias in the text to support your arguments. You should have the article and the notes you made from the previous class with you, but no dictionary.

Make sure to

a) write in complete sentences;

b) divide your essay into paragraphs (each paragraph should make one point and then give details and examples);

c) organise your points in a clear and logical order;

d) once you have finished the essay, check your writing and correct any spelling, vocabulary and grammar errors that you find (but do not use a dictionary).

Six of the 32 students elected to write the essay in pairs, and hence 29 essays were uploaded in Moodle. It should be noted that students who did not finish during the class or were absent from class were permitted to complete their work at home and/or during the next class, which is likely to affect the results of our study to some extent. The essays were then anonymised and uploaded in Moodle as a discussion forum message (with one forum for each student): the students were instructed to do as follows: 
Comment on these aspects: Does the essay answer the question well (explain why/why not)? Does the essay have a clear structure (are the points explained clearly and in a logical way?)? Can you find any errors in the spelling, vocabulary, or grammar (give examples if possible)? Try to give both positive and critical comments.

This resulted in reviews of all but three of the 29 essays (in other words three students did not take part), and this time two of the three abovementioned pairs chose to work together.

\subsection{The follow-up}

The students having fulfilled their part, we read through the essays and the peer reviews in order to find common successes and common errors in these texts, as well as to note any awareness of such errors by the peer reviewers. We then returned to present our findings to the class. As a further contribution after this final session, we uploaded some relevant undergraduate course material on essay writing in Moodle that could be used by the teacher and/or consulted by the students, along with exercises (with a key) on style, grammar and punctuation etc. that students might be encouraged to do.

\section{Analysis of the students' work}

\subsection{Aims and research context}

The main focus of the analysis was on vocabulary, as this is consistently identified as an area of weakness in student work by secondary school teachers. We approached this first by examining the frequency levels of the vocabulary that the students used. We then cross-referenced this to the Common European Framework of Reference (Council of Europe 2001). The aim was to find out about both their vocabulary knowledge, indicated by the frequency level of words they could produce and their ability to use them appropriately, and the approximate level of these words in terms of the Common European Framework of Reference (CEFR).

We began by looking at word frequency, because this is used as a guiding principle in language teaching pedagogy to identify the vocabulary that learners need to know to be able to function in English. Lists of the most frequent words of English in one thousand increments have been created from large-scale corpora such as the British National Corpus and the Corpus of Contemporary American English and are widely used as a point of reference in teaching materials. Learners need to become familiar with the most common words that they will meet as quickly as possible, and then continue to extend their knowledge to 
less frequent words. High frequency vocabulary has traditionally been characterised as the most frequent 2,000 word families (e.g. Read 2000; Schmitt 2000; Nation 2001) although more current research has revised this upwards to 23,000 word families in English (Schmitt and Schmitt 2014). How many words a learner needs to know, however, depends on what they need to do with the language, and this is by no means clear-cut. To read a range of authentic texts and newspapers with 98 percent text coverage (i.e. one word in 50 unknown), in the region of 8-9,000 word families will be needed (Nation 2006), whereas for a lower coverage of 95 percent (i.e. one word in 20 unknown) this drops to 45,000 (Laufer and Ravenhorst-Kalovski 2010). For listening comprehension at a conversational level with 95 percent coverage, familiarity with 2-3,000 word families has been suggested (Adolphs and Schmitt 2003), as spoken discourse typically contains a high proportion of high frequency words. Similarly, Webb and Rodgers (2009) found that 3,000 word families provided around 95 percent coverage of various types of TV programmes. (For a full review of vocabulary size and text coverage studies, see Schmitt and Schmitt 2014.)

It should be emphasised here that the figures above relate to word families known receptively. There are a number of aspects of word knowledge, and these are gained incrementally. A learner may recognise and understand a spoken word, and even be able to use it in conversation, but not know how to spell it. Equally, they may understand a word's meaning in a text, but be unable to apply it in the appropriate context in their own written work. Productive mastery of a word requires knowledge of a range of features including form, meaning, grammar, collocation, register, and associations (Nation 2001: 27). As such, it seems likely that the number of word families a learner knows productively will be a fraction of those known receptively. However, empirical studies have failed to reach a consensus on this relationship. Schmitt's (2014) review of the research in this area reported extremely varied findings; two of those he cites are Melka (1997), who found that 92 percent of words known receptively were also known productively, and Laufer (2005), whose study indicated that at the 5,000 frequency level only 16 percent of receptive vocabulary was known productively, while this increased to 35 percent at the 2,000 level. As Schmitt (2014) points out, the relationship between size and depth is extremely complex and difficult to measure, and no reliable method has been established.

While frequency levels are an important guiding factor in vocabulary acquisition, they are not the only indicator that needs to be taken into consideration. Some words have a higher learning burden than others; i.e. they are intrinsically more difficult to acquire. How difficult a word is depends on a range of intralexical and interlexical factors. Intralexical difficulty refers to the inherent diffi- 
culty of the word itself, which is driven by many features, ranging from word length and word form, nouns typically being the easiest and adverbs the most difficult, to features such as pronounceability, orthography, morphology, synformy and semantic features (abstractness, register, idiomaticity, polysemy) (Laufer 1997). The relationship between the first and second language, i.e. interlexical features, can also increase or ease learning burden, depending on language distance and the degree of congruency of a word use in the two languages. Lack of synonymy, for example, creates difficulties in a number of ways: relating polysemous words from one language to single-meaning words in the other; appreciating partial overlaps in meanings; allowing for metaphorical extension (Laufer 1990: 577-582). Cultural differences, too, may result in different connotative meanings or lexical voids (Laufer 1990: 582-583).

The second approach we took to assessing vocabulary level was to examine it with reference to the CEFR. This is a scale of proficiency ranging from basic (A1) to proficient (C2) users of language ${ }^{2}$, and detailed descriptors which outline exactly what a learner should be able to do at each level have been developed (Council of Europe 2011). These descriptors are intended to be interpreted within specific contexts; the CEFR does not attempt to list specific language features, i.e. which grammatical rules and vocabulary should be known at a certain level, and it cannot be used as a checklist of learning points. However, there has been a move to try to establish what grammatical and lexical items are typically learned at each CEFR level by the English Profile project, a collaborative project led by the Council of Europe. The English Profile website (http:// www.englishprofile.org) offers a public interface to access this information, in terms of both grammar and vocabulary. When a query is typed in, it shows examples of use of this language from examinations mapped to CEFR levels. For a vocabulary query, for example, a word may be shown used in different ways at different levels, illustrating the relative difficulty of the uses and the way it has been acquired. This can then inform us about what is suitable for learning at each level, and, conversely, what level a student is achieving if they use this language.

A further aim of the study was to get some insight into the students' awareness of their strengths and weaknesses when writing in English. Some of the errors in language in the student essays were 'mistakes', i.e. they were performance failures in applying language rules, whereas others were true 'errors', arising from a lack of knowledge of the correct rule (cf. Corder 1967). Including the peer review not only had benefits for the learners, as discussed below, but it also gave us a clearer overview of the state of the students' interlanguage (Selinker 1972), i.e. the system of language currently in use by the learners, as it 
showed us mistakes they were aware of and errors that they were not. This had important implications for the outcome of the study, as it highlighted areas where students needed awareness-raising activities in order to improve their language and writing skills.

A project comparable to ULE in terms of corpus compilation and applications for the material in upper secondary school teacher trainee courses (see Section 4) is the Uppsala Learner English Corpus (Johansson and Geisler 2009). The Uppsala Learner English Corpus (ULEC) was collected over several years by teacher trainees studying at Uppsala University, and comprises written work by students aged 14-19. The teacher trainees use the material "to form ideas on how to teach grammar and contextualise grammar in the classroom. They also use the corpus to investigate the knowledge of English grammar among junior and senior high school students" (Johansson and Geisler 2009: 181). Johansson and Geisler (2009: 183-185) report on findings of a number of student papers based on ULEC, which showed among other things that students of (what is now known as) English 6 were better than those studying what is now English 5 at verb forms (spelling, tense and agreement) and the use of noun plurals and the genitive, but were "more careless when dealing with spelling in general and punctuation", and suggested that students write like they speak, with "simple sentence structure and frequent use of discourse markers" (Johansson and Geisler 2009: 183-184). Key errors found in ULEC were in article usage, capitalisation, the 's-genitive, and, in particular, verb forms (primarily subject/verb agreement), which remain the errors found in first-term essays by university students. This clearly has implications for the teaching of grammar at upper (and lower) secondary school. Johansson and Geisler's own research using ULEC has focused on investigating syntactic development among L2 learners (see also Johansson and Geisler 2011).

Apart from the ULEC project, the present study does not have any direct precedents that we are aware of, but it is useful to relate the various strands of this project to other studies of secondary school English language learners. Regarding vocabulary, Stæhr (2008) examined vocabulary size in relation to the skills of listening, reading and writing among Danish secondary school students, finding a relatively strong relationship between learners' vocabulary size and the quality of their written compositions. His study highlights the importance of the 2,000 word threshold; he found that if learners did not know 2,000 word families, they performed below average in written composition. In his study, the majority of the learners had not reached this threshold despite seven years of English teaching (approximately 570 hours), and, in line with general research in vocabulary teaching (e.g. Nation 2001; Laufer 2005; Schmitt 2008), he con- 
cludes that there is a need to focus more explicitly on vocabulary learning in the second language classroom. Several studies have shown that lexical knowledge, both in terms of range and accuracy, has a direct correlation with how writing is rated (e.g. Engber 1995; Yu 2010).

Regarding the peer feedback aspect of the study, Berggren (2015) reports on the usefulness of peer feedback on L2 writing among lower secondary school students in Sweden aged 14-15. This study focused on the aspects of the writing that were improved as a result of peer feedback rather than the feedback students gave; it is evident that it was most effective in developing structure and organization, then content, with grammar and vocabulary least affected by it. However, it was found that the act of peer reviewing increased students' awareness of certain aspects of their own writing, reflecting previous studies (e.g. Lundstrom and Baker 2009; Rouhi and Azizian 2013) which acknowledge such benefits.

Error analyses are also relevant to our study (cf. the ULEC project described above). In their study into L1 and L2 student writing among high school students in the United States, Wilcox et al. (2014) found little difference in the type of errors made in written compositions by L1 and L2 students, with eight error types (spelling, capitalization, missing comma after introductory element (such as a clause or phrase), incorrect or inappropriate word, incorrect verb inflection, missing word, inappropriate or missing punctuation, and wrong form of the word) accounting for over half the errors in each group. However, not surprisingly, a higher error density was found in writing by L 2 students $(6.95$ errors per 100 words as compared to 4.07 for L1 writing). This study took place in the target language environment, where a higher proficiency level would be expected. Studies of English language learners in the L2 environment have similarly reported that many of the same errors occur, but include a stronger focus on cross-linguistic analysis, finding that the learners' L1 plays an important role. Olsen's (1999) study of Norwegian lower secondary school EFL students found that the majority of errors were intralingual, i.e. stemmed from L1 transfer, for example. In contrast, in a study of Swedish 16-year-old students of English, Köhlmyr (2003) found that overgeneralisation errors dominated, although L1 transfer was also an important contributor to learner errors.

Before examining the vocabulary levels of the students, and touching on their knowledge of particular aspects of grammar and text structure, we need to consider the expectations for students taking English 6 at upper secondary school in Sweden. According to the Swedish National Agency for Education (Skolverket) (2011a: 8-10), the requirements regarding oral and written production for the lowest pass grade (E) at the end of the school year are as quoted 
below (bold face in the original); we have added the text in square brackets, which gives the alternative requirements for the highest pass grade (A).

In oral and written communications of various genres, students can express themselves in a way that is relatively [-] varied, [balanced,] clear, and relatively [-] structured. Students can also express themselves with fluency and some [-] adaptation to purpose, recipient and situation. Students work on and make simple [well grounded and balanced] improvements to their own communications. In oral and written interaction in various, and more formal and complex contexts, students can express themselves clearly [, freely] with fluency, and with some [-] adaptation to purpose, recipient and situation. [...] Students discuss in basic terms [in detail and in a balanced way] some features in different contexts and parts of the world where English is used, and can also make simple [well developed and balanced] comparisons with their own experiences and knowledge.

Little is stated as regards specific competence in vocabulary and grammar, although the weaker students should be able to express themselves "in basic terms" and make "simple comparisons", whereas the higher grade is awarded to those who can express themselves "in detail" and in a "well developed" way. We see that students should be able to express themselves fluently, using clear and (relatively) varied language, and use appropriate language (to some extent) in a variety of contexts, as well as show some awareness that allows them to improve their spoken and written production. In terms of CEFR levels, with reference to vocabulary, the requirements for grades A to E could be interpreted to reflect B2. This is both as regards vocabulary range ("Has a good range of vocabulary for matters connected to his field and most general topics. Can vary formulation to avoid frequent repetition, but lexical gaps can still cause hesitation and circumlocution") and control ("Lexical accuracy is generally high, though some confusion and incorrect word choice does occur without hindering communication") (see Council of Europe 2001: 112). In general terms, the target CEFR level for English 6 is B2.1 (and B2.2 for English 7) according to the Swedish National Agency for Education (2011b): thus the expected level is towards the lower end of upper intermediate.

\subsection{Analysis of the students' vocabulary level}

The essays were examined to discover the vocabulary level of the class as a whole. To do this, we used the free online resource, Compleat Lexical Tutor (https://www.lextutor.ca), or more precisely the VocabProfiler VP-Compleat 
(see below). However, first it was important to only include the vocabulary that the students 'know', so we needed to exclude the vocabulary from the newspaper article that they were discussing in their essays. Thus, using the Text Lex Compare interface (http://www.lextutor.ca/cgi-bin/tl_compare/index.pl) available in Compleat Lexical Tutor, we saved the article in plain text format and uploaded it as a 'first text'; we then uploaded a file in plain text format containing all the anonymised essays as the 'second' or 'target text' (see Method 2 on the webpage http://www.lextutor.ca/cgi-bin/tl_compare/index.pl). The output included a list of words unique to the essays, i.e. words that were not found in the newspaper article. The next stage was to manually examine the list of unique words in context and delete all words that were proper nouns or adjectives (e.g. American, Clinton). The resulting list contained 827 unique words. Finally, to determine the vocabulary level we turned to the VocabProfiler VP-Compleat (http://www.lextutor.ca/vp/comp) and selected BNC-COCA-25 (based on both the British National Corpus and the Corpus of Contemporary American English, and consisting of 25 levels) and then pasted the word list into the input box and submitted the data for analysis. The results are shown in Table $1:^{3}$

Table 1: Frequency levels in thousand word (K) intervals for the unique vocabulary (types) in the student essays (raw figures and percentages)

\begin{tabular}{|l|cc|}
\hline Frequency level & \multicolumn{2}{|l|}{ Types } \\
\hline K1 words & 538 & $64 \%$ \\
\hline K2 words & 158 & $19 \%$ \\
\hline K3 words & 96 & $11 \%$ \\
\hline K4 words & 17 & $2 \%$ \\
\hline K5 words & 8 & $1 \%$ \\
\hline K6 words & 3 & $0.4 \%$ \\
\hline K7 words & 1 & $0.1 \%$ \\
\hline K8 words & 6 & $1 \%$ \\
\hline K9 words & 1 & $0.1 \%$ \\
\hline
\end{tabular}




\begin{tabular}{|c|c|c|}
\hline K10 words & 0 & \\
\hline K11 words & 0 & \\
\hline K12 words & 0 & \\
\hline K13 words & 2 & $0.3 \%$ \\
\hline K14 words & 0 & \\
\hline K15 words & 1 & $0.1 \%$ \\
\hline Off-list & 9 & $1 \%$ \\
\hline Total & 816 & $100 \%$ \\
\hline
\end{tabular}

The results show the types (i.e. the number of distinct words rather than tokens, i.e. the total number of occurrences of these words) displayed by the VocabProfiler. ${ }^{4}$ Table 1 shows that 83 percent of the words used in the essays fall into the top 2,000 most frequent word-levels (K1 and K2). As regards the less frequent word-levels, 11 percent of the words belong to vocabulary level K3, while the next level (K4) represents two percent of the data, and levels K5 and K8 account for 1 percent. Levels K6, K7, K9, K13 and K15 account for less than one percent.

The next step was to check each type of word using the English Profile interface (see Section 3.1). This was done by searching for each of the word types in the output from VocabProfiler to discover the CEFR level (see http:// www.englishprofile.org/wordlists). As we are interested in what vocabulary level the students have attained as a class, we ignored the first two thousand word levels (K1 and K2) and focused on the vocabulary at the 3,000-word level (K3) and above, which amounted to 127 types. The results are presented in Table 2 ("X" refers to words that were not found in the English Profiler): 
Table 2: CEFR levels for the vocabulary at K3 level and above in the student essays (raw figures and percentages)

\begin{tabular}{|l|cc|}
\hline Frequency level & \multicolumn{2}{|l|}{ Types } \\
\hline A2 & 2 & $2 \%$ \\
\hline B1 & 20 & $16 \%$ \\
\hline B1/B2 & 1 & $1 \%$ \\
\hline B2 & 37 & $29 \%$ \\
\hline C1 & 29 & $23 \%$ \\
\hline C2 & 13 & $10 \%$ \\
\hline X & 25 & $20 \%$ \\
\hline Total & $\mathbf{1 2 7}$ & $\mathbf{1 0 0} \%$ \\
\hline
\end{tabular}

The results shown in Table 2 suggest that the students' vocabulary range extends to $\mathrm{C} 2$ (proficient), but with the majority of the vocabulary falling into the B2 (upper intermediate) and, to a lesser extent, C1 (advanced) levels. This would essentially reflect the level implied by the Swedish National Agency for Education (see Section 3.1), and is particularly encouraging as the students are only in their first term of English 6. However, so far the results have not taken vocabulary that was used incorrectly into account. We therefore checked each type against the tokens in the student essays and labelled them as correct, incorrect or correct/incorrect (the latter group refers to mixed usage, i.e. words used correctly in some cases but in other cases misspelt, or used inappropriately in terms of meaning, collocation or syntactic form). The results are presented in Table 3: 
Table 3: CEFR levels and the usage of vocabulary at K3 level and above in the student essays (raw figures and row percentages)

\begin{tabular}{|c|c|c|c|c|c|c|c|c|}
\hline Frequency level & Corr & Isage & Mi & usage & Ince & usage & Total & \\
\hline $\mathrm{A} 2$ & 2 & $100 \%$ & 0 & & 0 & & 2 & $100 \%$ \\
\hline B1 & 17 & $85 \%$ & 1 & $5 \%$ & 2 & $10 \%$ & 20 & $100 \%$ \\
\hline $\mathrm{B} 1 / \mathrm{B} 2$ & 0 & & 1 & $\begin{array}{r}100 \\
\%\end{array}$ & 0 & & 1 & $100 \%$ \\
\hline B2 & 28 & $76 \%$ & 4 & $11 \%$ & 5 & $14 \%$ & 37 & $100 \%$ \\
\hline $\mathrm{C} 1$ & 21 & $72 \%$ & 3 & $10 \%$ & 5 & $17 \%$ & 29 & $100 \%$ \\
\hline $\mathrm{C} 2$ & 11 & $85 \%$ & 1 & $8 \%$ & 1 & $8 \%$ & 13 & $100 \%$ \\
\hline $\mathrm{X}$ & 16 & $64 \%$ & 1 & $4 \%$ & 8 & $32 \%$ & 25 & $100 \%$ \\
\hline Total & 95 & $75 \%$ & 11 & $9 \%$ & 21 & $17 \%$ & 127 & $100 \%$ \\
\hline
\end{tabular}

As can be seen in Table 3, which again shows types and not tokens, 75 percent of the vocabulary is used correctly, and only 17 percent of the vocabulary is not used correctly at all. The results appear to confirm the pattern in Table 2, that B2 and $\mathrm{C} 1$ account for the majority of types (28 and 21 respectively are used correctly), followed by $\mathrm{B} 1$ and $\mathrm{C} 2$. This indeed seems to place the students - as a class - around the expected level by the end of the school year. However, it should be noted (see also Section 2.2) that the essays were not written under exam conditions, and students may have had access to dictionaries or some may have used a spell-checker: due to an unforeseen scheduling change, most students did not have time to complete the essay during the assigned class time, as this was cut short: thus they were able to continue during the next class and/or at home. This might also partially account for the high percentage $(85 \%)$ of $\mathrm{C} 2$ level vocabulary (i.e. legitimate, psychiatrist, subtly, targetting, adverse, credibility, diagnosis, likewise and portrayed) being used correctly (the same percentage as found for vocabulary at B1 or lower-intermediate level). We should also stress here that there is of course a range of ability in the class, with some students leaning more towards the B1 level and others towards $\mathrm{C} 1$ and $\mathrm{C} 2$; it is also clear from the essays that some students hurried to complete the assignment, while others, as mentioned above, took more time and checked their language as requested (see Section 2.2). 
The input vocabulary from the article, as mentioned earlier, was removed from the data, as we could not tell if the use of such vocabulary demonstrated student knowledge. Interestingly, the key input word bias (a C2-level word used 31 times in the student essays), which was the topic of the assignment and thus not excluded from the data, was used incorrectly in over half the cases. This was mostly in contexts where biased was required (the word biased itself was used correctly in the majority of cases): possibly this reflects the students going by what they heard in the lectures (in class and in Moodle), in which they would of course not be able to distinguish the inflection -ed (i.e. /t/) in the repeated expression "biased towards". In only one other case was the wrong verb selected (decline for declined). Of the words that were labelled 'incorrect' or 'correct/ incorrect', the most common type of error was where the wrong word had been selected (e.g. revolving for involving, exempt for except and refrained for resisted). The second most common error was misspelling (e.g. furtermore, teory, and insidense for incidents); here again (mis)pronunciation of the words played some role in students' spelling.

\subsection{Student competence in and awareness of language and text features}

To assess the students' awareness of linguistic features, the peer reviews were assessed. There were a total of 26 peer reviews submitted; these averaged 76 words in length, ranging from 27 words to 168 words. Most of the students commented on a number of areas of competence in the essay they reviewed, and as requested they considered both successful features and identified areas for improvement. For each peer review we noted whether the comment related to e.g. structure, grammar or vocabulary, and whether they were positive or negative comments. The results are shown in Table 4:

Table 4: Number of positive and negative peer review comments relating to the different areas of competence

\begin{tabular}{|l|c|c|}
\hline Area of competence & Positive comments & Negative comments \\
\hline Content & 20 & 11 \\
\hline Structure & 16 & 9 \\
\hline Grammar & 8 & 12 \\
\hline Vocabulary & 7 & 7 \\
\hline Punctuation & 0 & $\mathbf{4 0}$ \\
\hline Total & $\mathbf{5 1}$ & \\
\hline
\end{tabular}


Overall, the number of positive comments (51) was greater than negative ones (40). The majority of the peer reviews began with a positive statement, often relating to overall performance or content, before giving more specific information. This accounts for the large number of positive comments on content (20), such as I think the essay gives a good summary about the situation concerning the election. Critical comments mainly related to lack of development, e.g. Most of the article doesn't really answer the question, it is only the last part that talks about who the article favors, or lack of clarity, e.g. I do not quite understand what their opinion is. The second area to receive a high number of positive comments was structure (16), where most of the positive comments were not specific, e.g. I think the essay has a very good structure, but appeared to relate to overall organisation. Some students referred to paragraphing, both directly, good paragraphing and indirectly, it's easy for the eyes to read this essay. Negative comments related to lack of or unclear conclusions, paragraphing, or simply that the structure is poor or weird or incoherent, e.g. that the text jumps from one point to the other and then back again.

For the language features, students made fewer comments overall. On grammar, students made more negative than positive comments. The positive comments were very general, e.g. uses decent grammar, as were most of the negative comments, e.g. some grammatical wrongs here and there. Some comments related to accuracy, with errors in word form and subject/verb agreement illustrated, but a tolerance of grammatical inaccuracy was implicit in some comments, e.g. some minor grammar errors but that happens. In some cases, the students identified incorrect grammar but did not correct or explain it. There were fewer comments on vocabulary, and these were also very general, with good words and good spelling the main positive comments. Negative comments were mainly related to spelling, but there was some awareness of both a lack of range, i.e. using the same words several times and inconsistency in register (The formality isn't consistent throughout the essay). Regarding punctuation, one student commented on a lack of capitalisation.

Considering the peer review comments in relation to our own assessment of the essays, there was consensus in a number of areas, particularly those the students had paid most attention to, i.e. content and structure. However, in terms of language awareness, we found a much greater divergence. The students placed emphasis on meaning over accuracy, and in general tolerated a high level of error: this is perhaps not surprising given the focus by the Swedish National Agency for Education (2011a) on communication and fluency, and the lack of explicit reference to vocabulary and grammar (see Section 3.1). There were many mistakes in basic grammar, notably subject/verb agreement errors, other 
errors with verb forms (cf. the findings based on ULEC), and confusion with existential there and anticipatory $i t$. It was clear from the peer review comments that the students lacked the metalanguage to explain these grammatical errors, although some students were able to identify them. Comments on range and formality in vocabulary were very much in the minority, with the focus on surface features, notably spelling. Many of the vocabulary errors we noted have been mentioned in Section 3.2, but other contextual mistakes with collocation (e.g. biased to, biased for) and register (e.g. for starters, badmouths) were evident. Whereas only one student made a comment relating to punctuation, we found a lack or misuse of commas, apostrophes and capital letters in the majority of the essays.

\subsection{Summary of results}

Our primary focus in this study was on vocabulary usage. Along with the expected high frequency vocabulary, we found that the students also successfully used lower frequency vocabulary. Analysis of the lexis used at these lower frequency levels $(\mathrm{K} 3+)$ demonstrated that the majority of these words were categorised by English Profile as being B2 / C1 level (52\% in total), although some extended into C2 level (10\%). Most words (75\%) were used correctly; errors tended to relate to word form and misspelling, the latter apparently influenced by (mis)pronunciation.

The second area we examined was the students' language awareness, through their ability to critique other students' writing. We found there was an emphasis on content and structure in the comments, and the majority of these were positive. Grammar attracted the most negative comments, although there was an inability to describe the problems effectively; we also noted a high tolerance of error. There were relatively few comments on vocabulary, and punctuation was essentially ignored.

As we have noted, this was a pilot study, and it was limited in a number of ways. The students who participated varied in their level of English proficiency and their degree of engagement with the study. As not all tasks were completed in a controlled classroom environment, there was potential to access dictionaries and other supports, so the texts submitted may not accurately reflect their productive lexical resource. A more extensive and controlled study would be needed to produce results which could be considered representative of this year group. 


\section{$4 \quad$ Implications of the project}

It was encouraging to see that the vocabulary used by the students was broadly in line with curriculum expectations at this level, and that students were prepared to take risks with vocabulary, recycling lexis from the input material and instructions and using words that were not fully known. However, there was evidence of a lack of awareness about issues relating to vocabulary. Few students commented on the range, appropriacy or form of words used in their peers' work, the majority commenting on other features, or, if they mentioned words, spelling was the focus. Furthermore, when the students used words known to be new, such as bias, they tended to make mistakes with form and collocation. This suggests that it would be of value to explicitly highlight such features, and raise awareness of the impact they have on the quality of writing. As new words are introduced, it is useful to consciously develop awareness of the range of information needed to use them - not only spelling and pronunciation but register, collocation, and connotations - and develop knowledge about the word family, its different forms, synonyms and antonyms. Although dedicated exercises in school textbooks may assist with this, published teaching materials tend to focus on form-meaning relationships and grammatical features (Brown 2010), which will only take students so far. In view of this, and given the non-finite nature of vocabulary learning, it is important that they are encouraged to find their own ways of developing lexical knowledge. For example, introducing students to concordances, which show words used in multiple contexts, can be a useful approach to raising awareness of different meanings and typical collocations (see, for example, Cobb 1997; Allan 2010). Getting students to track their vocabulary learning using notebooks (e.g. Schmitt and Schmitt 1995; Dubiner 2017) or computer or phone apps, whereby they can add further information as they learn more about new words, may also be helpful.

The quality of the peer review comments, and the fact that there were more positive than negative comments overall is similarly encouraging. The students showed an awareness of their achievements and an ability to identify key textual features that improved, or would improve, their work. In their comments about language, however, they appeared to lack the metalanguage to be specific, and it would be beneficial to explicitly teach them simple terms to describe common grammar errors, such as subject/verb agreement errors, wrong tense, missing punctuation etc. Providing students with a list of such terms for error correction, and giving them regular practice in using this to identify mistakes in peers' work would help to familiarise them with common errors. It would also help to raise awareness of the importance of language accuracy to improve the overall quality of their writing. 
In terms of the ULE assignments, we felt that the quality of students' work would have been more representative of their ability if we had added an additional step whereby students revised their own essays following peer review. Some of the assignments contained performance errors, i.e. typographical and grammatical slips that the writer could easily have self-corrected. This highlights the importance of drafting and re-drafting, a process that is typical of university-level work, and in future collaborations, we would anticipate including this stage before submission.

This leads us to the next step: to expand and develop the ULE project. We hope to continue our collaboration with the upper secondary school, but involving more teachers, and making the process more efficient in terms of time spent on the project by teachers, students and lecturers, and more productive. The long-term plan is to expand to further upper secondary schools in the region. In order for this to be feasible, the project needs to be revamped in a number of ways. Something we can learn from the ULEC project (see Johansson and Geisler 2009) is that it is advantageous if the students write their essays directly into an easily accessible online interface. This could be done for both the first draft and the revised draft post peer review. Organising our input into the class schedules with the participating teachers well in advance will be essential. Refining the instructions and materials for the assignment (because for upper secondary students, less is probably more) is essential to maximise time spent on the assignment rather than on the introduction to the project and the learning platform, and thus prevent a potential loss of enthusiasm on the students' part. Recording short lectures that can be viewed at home or in class, simplifying the log-in process, and making the rewards of the project more transparent to upper secondary school students are other things to be considered, all of which would help make a collaborative project with more than one or two classes viable.

A major part of the ULE project is the creation of corpus material for didactic and linguistic research by teacher trainees, other university students, and researchers. The ULEC project has already shown the value of similar material in teacher trainee courses with regard to teaching grammar to upper secondary school students, and in their teacher trainees' degree projects, but, as we have demonstrated, other aspects of language acquisition, such as vocabulary, can also be fruitfully explored. With the expansion of the ULE corpus, it will then be worthwhile adding annotation to facilitate searches. The ULE corpus material can also be used in teacher trainee exercises in assessing and grading upper secondary school students' written work. Developing and extending the ULE project also means that the corpus material will continually expand, which will allow both synchronous and diachronous studies of the material. 


\section{Acknowledgements}

The authors would like to thank the anonymous reviewers for their helpful feedback on this article; any remaining errors are, of course, our own. Moreover, this publication has made use of the English Vocabulary Profile. This resource is based on extensive research using the Cambridge Learner Corpus and is part of the English Profile programme, which aims to provide evidence about language use that helps to produce better language teaching materials. See http:// www.englishprofile.org for more information.

\section{Notes}

1. The ULE project was funded by a grant by Mid-Sweden University for research into upper secondary school English, which financed the work of the three staff members employed by Mid-Sweden University. The upper secondary school teacher and students contributed to the project during their regular, scheduled English classes.

2. Different labels have been used for the levels. The current CEFR labels (see Council of Europe 2001: 23) are as follows: A = Basic User (A1 = Breakthrough; A2 = Waystage); $\mathrm{B}=$ Independent User $(\mathrm{B} 1=$ Threshold; $\mathrm{B} 2=$ Vantage); $\mathrm{C}=$ Proficient User ( $\mathrm{C} 1$ = Effective Operational Proficiency; $\mathrm{C} 2$ $=$ Mastery). A more transparent labelling would be Basic, Intermediate and Advanced. Thus for our purposes, we consider B2 and B1 respectively as upper and lower intermediate, $\mathrm{C} 1$ as advanced (cf. the Cambridge English: Advanced exam) and C2 as proficient (cf. the Cambridge English: Proficiency exam).

3. Note that all percentages in the tables have been rounded-off to the nearest decimal (except in cases where this would result in $0 \%$ ).

4. The VocabProfiler treats words such as don't and can't as two words, i.e. $d o$ and not, and can and not. Thus the 827 words inputted are reduced to 816 in the output (as the words included in the contractions are already represented in the input list). The Off-list refers to words not found in both source corpora (and proper nouns, but we removed these in advance of the VocabProfiler analysis). 


\section{References}

Adolphs, Svenja and Norbert Schmitt. 2003. Lexical coverage of spoken discourse. Applied Linguistics 24 (4): 425-438. doi:10.1093/applin/24.4.425

Allan, Rachel. 2010. Concordances versus dictionaries: Evaluating approaches to word learning in ESOL. In R. Chacón-Beltrán, C. Abello-Contesse, M. Mar Torreblanca-López and M. Dolores López-Jiménez (eds.). Further insights into non-native vocabulary teaching and learning, 112-125. Clevedon: Multilingual Matters.

Berggren, Jessica. 2015. Learning from giving feedback: A study of secondarylevel students. ELT Journal 69 (1): 58-70. doi:10.1093/elt/ccu036

Brown, Dale. 2010. What aspects of vocabulary knowledge do textbooks give attention to? Language Teaching Research 15 (1): 83-97. doi:10.1177/ 1362168810383345

Cobb, Tom. 1997. Is there any measurable learning from hands-on concordancing? System 25 (3): 301-15.

Cobb, Tom. Compleat Lexical Tutor [website]. Accessed 1 May 2017 at http:// www.lextutor.ca

Cobb, Tom. Compleat Web VP! [computer program]. Accessed 1 May 2017 at http://www.lextutor.ca/vp/comp

Cobb, Tom. Text Lex Compare v.3 [computer program]. Accessed 1 May 2017 at http://www.lextutor.ca/cgi-bin/tl_compare

Corder, Stephen Pit. 1967. The significance of learner's errors. IRAL-International Review of Applied Linguistics in Language Teaching 5 (4), 161-170.

Council of Europe. 2001. Common European framework of reference for languages: Learning, teaching, assessment. Cambridge: Cambridge University Press.

Dubiner, Deborah. 2017. Using vocabulary notebooks for vocabulary acquisition and teaching. ELT Journal 71: 456-466. doi:10.1093/elt/ccx008

Engber, Cheryl. 1995. The relationship of lexical proficiency to the quality of ESL compositions. Journal of Second Language Writing 4: 139-155.

English Profile. 2012. English Vocabulary Profile [website]. Accessed 1 May 2017 at http://vocabulary.englishprofile.org/staticfiles/about.html

Johansson, Christine and Christer Geisler. 2009. The Uppsala Learner English Corpus: A new corpus of Swedish high school students' writing. In A. Saxena and Å. Viberg (eds.). Multilingualism: Proceedings of the 23rd Scandinavian Conference of Linguistics: Uppsala University, 1-3 October 2008, 181-190. Uppsala: Acta Universitatis Upsaliensis. 
Johansson, Christine and Christer Geisler. 2011. Syntactic aspects of the writing of Swedish L2 learners of English. In J. Newman, H. Baayen and S. Rice (eds.). Corpus-based studies in language use, language learning, and language documentation, 139-155. Amsterdam: Rodopi.

Köhlmyr, Pia. 2003. To err is human...An investigation of grammatical errors in Swedish 16-year-old learners' written production in English. Göteborg: Göteborg University.

Laufer, Batia. 1990. Words you know: How they affect the words you learn. In J. Fisiak (ed.). Further insights into contrastive analysis, 573-593. Amsterdam / Philadelphia: Benjamins.

Laufer, Batia. 1997. What's in a word that makes it hard or easy: Some intralexical factors that affect the learning of words. In N. Schmitt and M. McCarthy (eds.). Vocabulary: Description, acquisition and pedagogy, 140-155. Cambridge: Cambridge University Press.

Laufer, Batia. 2005. Focus on form in second language vocabulary learning. In EUROSLA Yearbook 5: 223-250. doi: 10.1075/eurosla.5.11lau

Laufer, Batia and Geke C. Ravenhorst-Kalovski. 2010. Lexical threshold revisited: Lexical text coverage, learners' vocabulary size and reading comprehension. Reading in a Foreign Language 22 (1): 15-30.

Lundstrom, Kristi and Wendy Baker. 2009. To give is better than to receive: The benefits of peer review to the reviewer's own writing. Journal of Second Language Writing 18 (1): 30-43. doi:10.1016/j.jslw.2008.06.002

Melka, Francine. 1997. Receptive vs. productive aspects of vocabulary. In N. Schmitt and M. McCarthy (eds.). Vocabulary: Description, acquisition, and pedagogy, 84-102. Cambridge: Cambridge University Press.

Nation, I. S. P. 2001. Learning vocabulary in another language. Cambridge: Cambridge University Press.

Nation, I. S. P. 2006. How large a vocabulary is needed for reading and listening? Canadian Modern Language Review 63 (1): 59-82.

Olsen, S. 1999. Errors and compensatory strategies: A study of grammar and vocabulary in texts written by Norwegian learners of English. System 27 (2): 191-205. doi:http://dx.doi.org/10.1016/S0346-251X(99)00016-0

Read, John. 2000. Assessing vocabulary. Cambridge: Cambridge University Press.

Rouhi, Afsar and Elnaz Azizian. 2013. Peer review: Is giving corrective feedback better than receiving it in L2 Writing? Procedia - Social and Behavioral Sciences 93: 1349-1354. doi:10.1016/j.sbspro.2013.10.042 
Schmitt, Norbert. 2000. Vocabulary in language teaching. Cambridge: Cambridge University Press.

Schmitt, Norbert. 2008. Instructed second language vocabulary learning. Language Teaching Research 12: 329-363. doi:10.1177/1362168808089921

Schmitt, Norbert. 2014. Size and depth of vocabulary knowledge: What the research shows. Language Learning 64 (4): 913-951. doi:10.1111/ lang. 12077

Schmitt, Norbert and Diane Schmitt. 1995. Vocabulary notebooks: Theoretical underpinnings and practical suggestions. ELT Journal 49 (2): 133-143.

Schmitt, Norbert and Diane Schmitt. 2014. A reassessment of frequency and vocabulary size in L2 vocabulary. Language Teaching 47 (4): 484-503. doi:10.1017/S0261444812000018

Selinker, Larry. 1972. Interlanguage. IRAL - International Review of Applied Linguistics in Language Teaching 10 (1-4): 209-232. doi:10.1515/ iral.1972.10.1-4.209

Stæhr, Lars Stenius. 2008. Vocabulary size and the skills of listening, reading and writing. Language Learning Journal 36 (2): 139-152. doi:10.1080/ 09571730802389975

Swedish National Agency for Education (Skolverket). 2011a. Curriculum for the English subject at upper secondary school. https://www.skolverket.se/ polopoly_fs/1.209313!/English\%20120912.pdf

Swedish National Agency for Education (Skolverket). 2011b. Om ämnet Engelska. https://www.skolverket.se/laroplaner-amnen-och-kurser/gymnasieutbildning/ gymnasieskola/sok-amnen-kurser-och-program/subject.htm?subjectCode=ENG

Webb, Stuart and Michael P. H. Rodgers. 2009. Vocabulary demands of television programs. Language Learning 59 (2): 335-366. doi:10.1111/j.14679922.2009.00509.x

Wilcox, Kristen Campbell, Robert Yagelski and Fang Yu. 2014. The nature of error in adolescent student writing. Reading and Writing 27 (6): 1073-1094. doi:10.1007/s11145-013-9492-x

Yu, Guoxing. 2010. Lexical diversity in writing and speaking task performances. Applied Linguistics 31 (2): 236-259. 